\title{
Qualidade Hidrológica e Ambiental de uma Microbacia Urbana de Abastecimento Público de Água na Amazônia Brasileira
}

Santarém é o terceiro município com o pior sistema de saneamento básico do país, onde dejetos residenciais fluem para fossas sépticas ou negra ou são lançados em natura nos igarapés. Complementar a isso, a bacia do Tapajós, está em área geologicamente susceptível à infiltração de água superficial que pode assim contaminar o lençol freático, fonte básica de água para o município. A urbanização desordenada, pode tornar-se um fator potencial de vulnerabilidade hídrica da microbacia do Irurá. Este estudo teve por objetivo realizar o levantamento das condições hidrológiças e ambientais da microbacia urbana do Irurá. Foram definidos cinco pontos amostrais ao longo da microbacia. Em cada um deles foi demarcado um trecho de 50 metros, onde foram medidas a largura do canal, profundidade, $\mathrm{pH}$, condutividade, oxigênio dissolvido - OD, turbidez, temperatura da água e a vazão. Também, foram feitas análises metros, onde foram medidas a largura do canal, profundidade, $\mathrm{pH}$, condutividade, oxigennio dissolvido - OD, turbidez, temperatura da agua e a vazão. Tamberm, foram feitas analises
microbiológicas da água e Índice de Integridade Habitat - IIH, além das características físicas da microbacia. Os dados foram coletados no período menos chuvoso (outubro de2015) e no microbiológicas da água e Índice de Integridade Habitat - IIH, alèm das características fisicas da microbacia. Os dados foram coletados no período menos chuvoso (outubro de2015) e no período chuvoso (maio e junho de 2016). As nascentes apresentaram pH ácido, e foi verificado para os demais pontos da microbacia Irurá um nível de OD abaixo daquele estabelecido pela
resolução CONAMA №357/2005. Foram encontradas as maiores concentrações de coliformes termotolerantes e com a presença de Escherichia coli no ponto I03. Nos pontos I03 e 104 verificou-se os maiores valores de temperatura da água, condutividade e turbidez. Apenas os parâmetros pH, OD, condutividade, turbidez, profundidade e vazão apresentaram variação sazonal. Os pontos 104 e 105 foram considerados degradados. Em relação aos elementos estruturais do canal, o ponto 104 foi o que apresentou menor profundidade, os pontos 104 e 105 apresentaram maior largura e consequentemente, menores vazões. A vazão $(\mathrm{r}=0,90 ; \mathrm{p}=0,005)$ teve correlação positiva significativa com IIH, os maiores valores de vazão foram encontrados a montante da bacia e os menores a jusante. Foi possivel, captar o índice de degradação ambiental ao longo da microbacia do Irurá causada pela urbanização e a falta de saneamento ambiental. Ações para prevenir a degradação nos ambientes considerados íntegros e para minimizar e reverter as fontes de impacto que promovem a degradação da microbacia do Irurá são necessárias.

\section{Hydrological and environmental quality of an urban microbasin used in public water supply in the Brazilian Amazon}

\begin{abstract}
Santarém is municipality with the third worst system of basic sanitation in the country, where residential waste flows to septic or black cesspools or are released in natura into the streams. Moreover, the Tapajós basin is in an area geologically susceptible to infiltration of surface water that can contaminate the water table, a basic source of water for the municipality. Disordered urbanization may become a potential water vulnerability factor in the Irurá microbasin. The objective of this study was to survey the hydrological and environmental conditions of the Irurá urban microbasin. Five sampling points were defined along the microbasin. In each one it was marked a 50-meter stretch, along which were measured the channel width, depth, $\mathrm{pH}$, conductivity, dissolved oxygen - DO, turbidity, water temperature and flow. Also, water microbiological analyzes and Habitat Integrity Index - HII were done, besides the physical characteristics of the microbasin. The data were collected in the least rainy period (October 2015) and in the rainy season (May and June 2016). The springs presented acidic $\mathrm{pH}$, and for the other points of the Irurá microbasin, the level of DO was below the one established by CONAMA Resolution №357/2005. The highest concentrations of thermotolerant coliforms and the presence of Escherichia coli were found at the point 103 . At the points 103 and 104 the highest values of water temperature, conductivity and turbidity were found. Only pH, DO, conductivity, turbidity, and depth and flow parameters showed seasonal variation. Points 104 and 105 were considered degraded. Regarding the structural elements of the channel, the point 104 was the one that presented the smaller depth, the points 104 and 105 presented bigger width and consequently, smaller flow rates. The flow rate $(r=0.90, p=0.005)$ had a significant positive correlation with presented the smaller depth, the points 104 and 105 presented bigger width and consequently, smaller flow rates. The flow rate $(r=0.90, p=0.005)$ had a significant positive correlation with
HII, the highest flow values were found upstream and the lowest values downstream. It was possible to detect the rate of environmental degradation along the Irurá microbasin caused by urbanization and lack of environmental sanitation. The HII presented as a useful tool to estimate the environmental quality along the microbasin, indicating the loss of flow downstream of the basin caused by environmental degradation. Actions are necessary to prevent degradation in the environments considered to be intact and to minimize and reverse impact sources that promote degradation of the Irurá microbasin.
\end{abstract}

Keywords: Water quality; Urban streams; Environmental degradation.

Topic: Engenharia de Recursos Hídricos

Reviewed anonymously in the process of blind peer.

Gedinara Paiva dos Santos (D)

Universidade Federal do Oeste do Pará, Brasil

http://lattes.cnpq.br/3313094495956562

http://orcid.org/0000-0001-8248-5635

narapaivasantos@gmail.com

Leidiane Leão de Oliveira (iD

Universidade Federal do Oeste do Pará, Brasil

http://lattes.cnpq.br/5016148560650320

http://orcid.org/0000-0002-5995-9107

leidianeoli@gmail.com

Graciene do Socorro Taveira Fernandes (iD

Universidade Federal do Oeste do Pará, Brasil

http://lattes.cnpq.br/9121021285937589

http://orcid.org/0000-0002-2710-4251

gracienefernandes@hotmail.com

6

DOI: 10.6008/CBPC2179-6858.2020.004.0014
Received: 09/05/2020

Approved: 02/06/2020

\author{
Ione lolanda dos Santos (ib) \\ Universidade Federal do Oeste do Pará, Brasil \\ http://lattes.cnpq.br/0591114860826667 \\ http://orcid.org/0000-0002-4159-5659 \\ ione iolanda@hotmail.com \\ Rodolfo Maduro Almeida (iD \\ Universidade Federal do Oeste do Pará, Brasil \\ http://lattes.cnpq.br/1527651015984510 \\ http://orcid.org/0000-0003-4564-825X \\ rodolfomaduroalmeida@gmail.com \\ Elton Raniere da Silva Moura (iD \\ Universidade Federal do Oeste do Pará, Brasil \\ http://lattes.cnpq.br/3955051826107598 \\ http://orcid.org/0000-0003-3309-8641 \\ eltonranieremoura@gmail.com
}

Referencing this:

SANTOS, G. P.; OLIVEIRA, L. L.; FERNANDES, G. S. T.; SANTOS, I. I.; ALMEIDA, R. M.; MOURA, E. R. S.. Qualidade Hidrológica e Ambiental de uma Microbacia Urbana de Abastecimento Público de Água na Amazônia Brasileira. Revista Ibero Americana de Ciências Ambientais, v.11, n.4, p.154-168, 2020. DOI: http://doi.org/10.6008/CBPC21796858.2020 .004 .0014 


\section{INTRODUÇÃO}

A bacia Amazônia é a maior bacia hidrográfica do mundo, com uma área aproximada de $6000 \mathrm{~km}^{2} \mathrm{e}$ têm 1100 afluentes, o que se dá por uma densa rede de drenagem entrecortando uma vasta região geográfica com rios, lagos e igarapés de pequeno a grande porte que compõe essa região (BRASIL, 2006). Os rios Amazônicos de pequena ordem são definidos como Igarapés (em tupi, significa 'caminho da canoa'). Os igarapés compõem interfaces aquático-terrestres, onde suas características ambientais (biodiversidade, hidrologia e qualidade da água) dependem da floresta ao seu redor (mata ciliar) (CARVALHO, 2011; MARMONTEL et al., 2012; GUARIDO, 2014; CARVALHO et al., 2016). A retirada da floresta primária provoca de forma direta a erosão do solo, perda de nutrientes e compactação do solo, além da perda de biodiversidade, redução do ciclo da água e contribui para o aquecimento global (MENDONÇA, 2001; FEARNSIDE, 2005; GALUCH, 2007; ANJOS, 2007; CORRÊA et al., 2012).

O Código Florestal Brasileiro Lei n. 4.771, de 15 de setembro de 1965, define a importância da vegetação das zonas ripárias, as mesmas são legalmente protegidas através da instituição de Áreas de Preservação Permanente (APPs). Atualmente regulamentada pela Lei $\mathrm{N}^{\circ}$ 12.651, de 25 de maio de 2012, que considera Área de Preservação Permanente, em zonas rurais ou urbanas. As faixas marginais de qualquer curso d'água natural perene e intermitente, excluídos os efêmeros, desde a borda da calha do leito regular, em largura mínima de 30 (trinta) metros, para os cursos d'água de menos de 10 (dez) metros de largura; 50 (cinquenta) metros, para os cursos d'água que tenham de 10 (dez) a 50 (cinquenta) metros de largura (BRASIL, 2012). Neste contexto, a cobertura vegetal é importante, pois, interfere nos mecanismos de transportes de águas superficiais e subterrâneas, mantem a integridade dos solos reduzindo a erosão e é fundamental para recarga dos aquíferos e manutenção da rede de igarapés (TUCCI, 2009; TARGA, 2012).

Desse modo, a urbanização desordenada, pode tornar-se um fator potencial de vulnerabilidade hídrica, uma vez que o crescimento urbano não é acompanhado de serviços de saneamento básico (ANA, 2005; ESTEVES, 2011; MONTEIRO et al., 2011). Segundo os dados do IBGE de taxa de crescimento 2000 a 2030, o estado do Pará é uma das regiões com uma das maiores taxas de crescimento populacional, comparado com outras regiões do Brasil. Neste sentido, Santarém desponta como o terceiro município mais populoso do Pará o que ocasiona a expansão urbana da cidade, de forma desordenada. Segundo o novo Ranking do Saneamento Básico (SNIS, 2015), Santarém é o 3o município com o pior sistema de saneamento básico do país, onde dejetos residenciais fluem para fossas sépticas ou negra ou são lançados em natura nos igarapés. Complementar a isso, a bacia do Tapajós, está em área geologicamente susceptível à infiltração de água superficial que pode assim contaminar o lençol freático, fonte básica de água para o município.

O monitoramento da qualidade da água é uma ferramenta estratégica na Gestão de Recursos Hídricos que embasa a tomada de decisão desde a outorga, cobrança, paralisação, interdição de empreendimento ou de praia ou igarapés impróprios ao uso, manejo de bacias hidrográficas, aplicação de multas, até ações revitalizadas, pois, orienta como background, ultrapassagem de padrões, e alterações de tendência (PARÁ, 2012). 
Diante das ameaças a integridade ambiental destes mananciais este estudo teve como objetivo fazer o levantamento das condições hidrológicas e ambientais de uma microbacia importante na cidade de Santarém como subsídio a recuperação e/ou preservação dessas águas e os resultados subsidiarão ações para a gestão dessas microbacias.

\section{MATERIAIS E MÉTODOS}

Localizada no município de Santarém, no estado Pará. Especificamente, foram definidos para este trabalho 5 pontos amostrais, sendo dois pontos são nascentes e os outros três estão distribuídos ao longo da microbacia do Irurá, abrangendo os bairros Cambuquira e Santarenzinho (Figura 1). Para cada ponto amostral foi estabelecido seu código específico (Tabela 1).
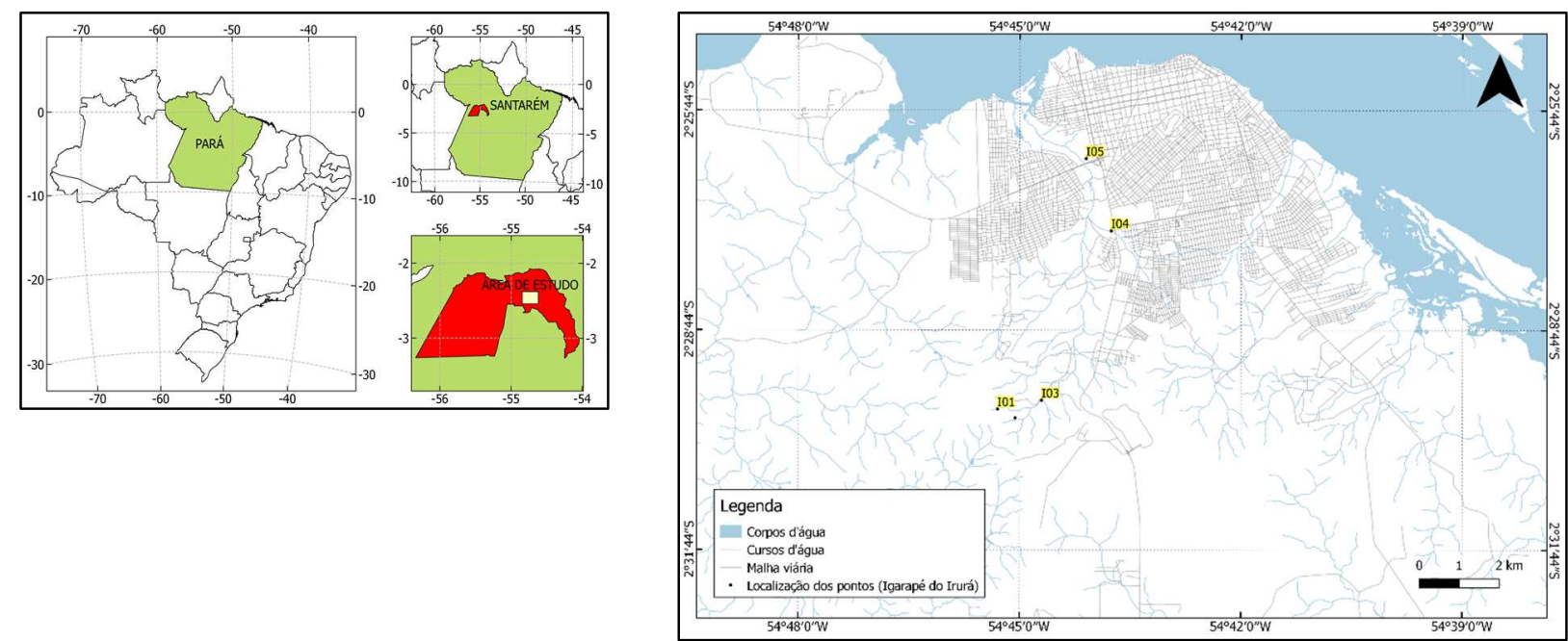

Figura 1: Mapa de localização dos cinco pontos de coleta ao longo da microbacia hidrográfica urbana do Irurá, Santarém/PA.

Tabela 1: Descrição dos pontos de coleta da microbacia hidrográfica Irurá.

\begin{tabular}{|l|l|l|l|l|}
\hline Bacia & Código & Características & Latitude & Longitude \\
\hline \multirow{4}{*}{ Irurá } & 101 (nasc. 1) & Trecho da cachoeira Rocha Negra & -2.497 & -54.755 \\
\cline { 2 - 6 } & 102 (nasc. 2) & Nascente represada (área particular) & -2.499 & -54.751 \\
\cline { 2 - 6 } & 103 & Depois do balneário (área particular) & -2.495 & -54.745 \\
\cline { 2 - 6 } & 104 & BR 163 & -2.456 & -54.729 \\
\cline { 2 - 6 } & 105 & Rodovia Fernando Guilhon & -2.44 & -54.735 \\
\hline
\end{tabular}

Em todos os Cinco pontos para coleta dos dados foi demarcado um trecho de 50 metros, onde foram feitas as medidas de zona ripária (índice de integridade Ambiental e cobertura vegetal média), do canal (vazão, largura e profundidade médias) e da água (químicas: pH, condutividade, oxigênio dissolvido e turbidez médios; físico: temperatura média) conforme o protocolo do projeto igarapés Mendonça et al. (2005). Além de coletas de amostras para análise de coliformes totais e termotolerantes, pela técnica dos tubos múltiplos conforme Standard Methods for the Examination of Water and Wastewater (APHA, 2002). As coletas foram feitas no período menos chuvoso ( 6 a $28 / 10 / 2015$ ) e chuvoso (4/5 a 29/06/2016) no projeto igarapés urbano (Edital universal/CNPq/2014).

Para avaliar a integridade ambiental foi utilizado Índice de Integridade do Habitat - IIH proposto por Nessimian et al. (2008) modificado por Bleich et al. (2014), que leva em consideração as características 
ambientais e o uso do solo na área de estudo. Nessimian et al. (2008) propõem 12 questões que visam responder os impactos de uso e ocupação do solo e que foram respondidas em campo de acordo com as características ambientais observadas do local; neste índice os valores próximos de 100 indicam ambientes muito conservados. Os igarapés que apresentaram valores de IIH $(<50)$ são classificados como ambientes de degradados, já os igarapés com valores intermediários (50 à 85) apresentam em seu canal ou entorno algum tipo de modificação imposta pelo homem porém ainda apresentam algumas características físicas naturais em alguns trechos, os igarapés com valores de IIH (85 a 100) apresentaram características físicas e biológicas naturais ainda quase inalteradas com poucos indícios de atividades antrópicas no entorno (OLIVEIRA JUNIOR et al., 2013; NESSIMIAN et al., 2008) (Tabela 2).

Tabela 2: Classificação do Índice de Integridade do Habitat - IIH por faixa avaliada, categoria, índice e observações do estado de conservação do ambiente adaptado de Nessimian et al. (2008) e Oliveira Júnior et al. (2013).

\begin{tabular}{|c|c|c|c|}
\hline IIH (\%) & ÍNDICE & CATEGORIA & ESTADO \\
\hline $\begin{array}{ll}100 & a \\
85 & \end{array}$ & Íntegro & Ótimo & $\begin{array}{l}\text { Apresentaram características físicas e biológicas naturais ainda quase inalteradas com } \\
\text { poucos indícios de atividades antrópicas no entorno. }\end{array}$ \\
\hline $\begin{array}{ll}85 & a \\
50\end{array}$ & Alterado & Regular & $\begin{array}{l}\text { Apresentam em seu canal ou entorno algum tipo de modificação imposta pelo homem, } \\
\text { porém ainda apresentam algumas características físicas naturais em alguns trechos. }\end{array}$ \\
\hline$<0,50$ & Degradado & Ruim & São classificados como ambientes de alto grau de perturbação. \\
\hline
\end{tabular}

Para avaliação dos parâmetros físico-químicos em relação a sazonalidade foram utilizados gráficos 'boxplot', que expressam de forma concisa a variação de cada parâmetro entre os pontos e a variabilidade ao longo do período sazonal. O que torna uma ferramenta muito útil, já que é possível avaliar de forma simplificada: mínimo, máximo, quantis e a mediana. As análises e saídas gráficas foram geradas no ambiente estatístico R. Para detectar a intensidade de relação entre as variáveis ambientais dos pontos amostrados da microbacia. Medidas de tendência central das variáveis foram testadas através da análise não paramétrica correlação de Spearman, no programa estatístico R (R CORE TEAM, 2015).

Para o delineamento da microbacia foi realizado o levantamento e georreferenciamento com o auxílio de um GPS (E-Trex 10 Garmim). Em seguida, foi elaborada com uso do software livre QGIS, versão 2.16.0, a partir dos dados do Shuttle Radar Topographic Mission (SRTM) uma imagem georreferenciada dos pontos na microbacia do igarapé Irurá. Utilizando fórmulas já existentes para o cálculo de parâmetros morfométricos como: Área de drenagem, largura, comprimento, perímetro. Em seguida foram calculados o Fator Forma - FF, índice de compacidade - KC e Índice de Circularidade - IC, estas variáveis expressam as características físicas da bacia, dependendo da forma a bacia pode ter maior a tendência a sofrer enchentes, estas variáveis tem relação direta com a resposta hidrológica da microbacia.

\section{RESULTADOS}

\section{Caracterização da microbacia}

Através do mapa de drenagem da bacia foi possível determinar algumas características físicas, tais como, área, largura e comprimento da bacia, assim como, o comprimento do canal principal. Além, de georreferenciar e delimitar a microbacia do Irurá (Figura 2). 


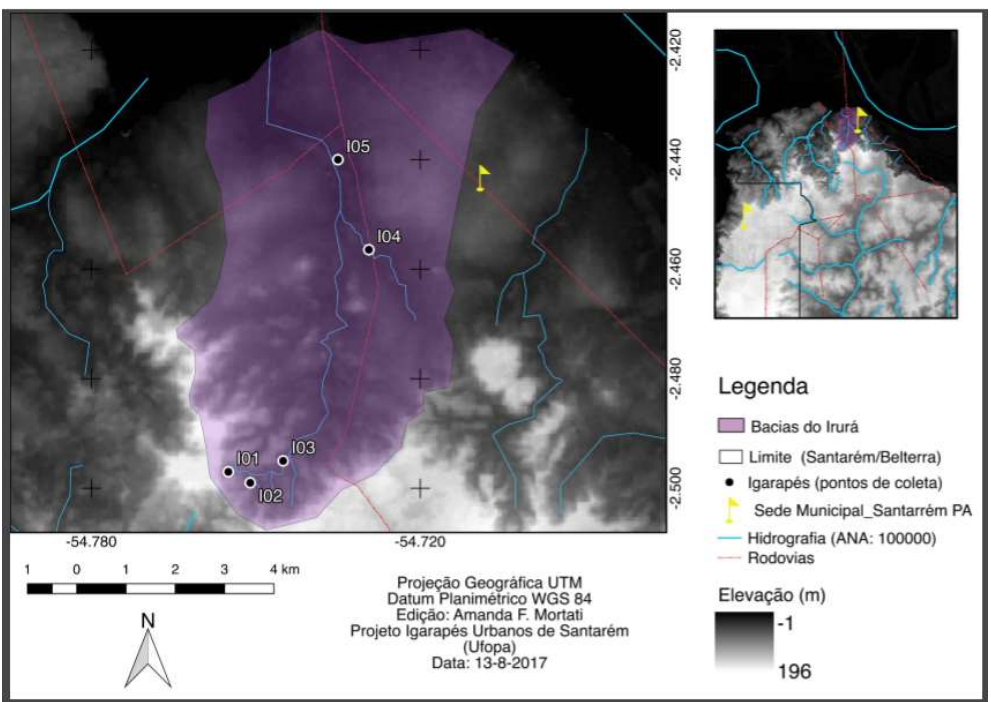

Figura 2: Mapa da microbacia de drenagem do Igarapé Irurá (lilás), Santarém/PA. Os pontos identificados representam pontos de coleta deste estudo.

A bacia do igarapé do Irurá tem 45,94 $\mathrm{Km}^{2}$ de área, largura média de 5,19 km, comprimento de 9,46 km e comprimento do canal principal de 10,74 km. O Fator Forma - FF foi de 1,2, o Índice de Compacidade KC foi de 1,2 e o Índice de Circularidade - IC de 0,7. Estes resultados demonstram que a microbacia do Irurá tem formato mais circular e propensão a sofrer enchentes.

\section{Integridade ambiental}

As duas nascente apresentaram ambientes com pouca perturbação ambiental, classificadas como íntegras 101(90\%) e 102(90,3\%) (Tabela 03). Nos pontos onde o índice de integridade apresenta porcentagem abaixo de $78 \%$ há forte perturbação do meio ambiente como nos pontos $103(74 \%)$ igarapé com pouca mata ciliar, proximidade com a estrada, casas, recebe visitantes que depositam seus resíduos (lixos) no corpo d'água, 104 (58\%) ambiente perto da BR163 recebe grande efluentes urbanos, forte degradação na vegetação e no solo. O ponto 105 (40\%) têm proximidade com bairros populosos e sem rede de drenagem eficientes, que fazem que esse ambiente tenha grande entrada de resíduos urbanos. Entretanto, na nascente Ponto Represado 102, onde o local é bastante alterado fisicamente, por exemplo, por meio de barragens que foram colocadas, o índice de integridade ambiental se apresentou em 90\%. Podemos atribuir a esse resultado a forte capacidade do meio de se recuperar (Figura 3).

Tabela 3: Valores do índice de integridade ambiental coletados em cada ponto amostrado da bacia do Irurá.

\begin{tabular}{|l|l|l|l|l|}
\hline Bacia & Código & Integridade (\%) & Integridade & Índice \\
\hline \multirow{4}{*}{ Irurá } & 101 & 90,0 & Integro & Ótimo \\
\cline { 2 - 6 } & 102 & 90,3 & Integro & Ótimo \\
\cline { 2 - 6 } & 103 & 74,0 & Alterado & Regular \\
\cline { 2 - 5 } & 104 & 58,0 & Alterado & Regular \\
\cline { 2 - 5 } & 105 & 40,0 & Degradado & Ruim \\
\hline
\end{tabular}

De maneira geral, a integridade ambiental foi verificada epenas em duas nascentes, onde o ambiente foi considerado íntegro. A nascente (102) que apresenta maior integridade é uma área particular e proprietario mantém a mata ciliar e sabe sobre a importancia da mesma, informações estas verificadas em campo. A segunda nascente (I01), encontra-se em área livre, porém, serve de recreação por apresentar uma 
pequena cachoeira, também, foi notado no local a queima da mata ciliar, pois este local também serve para cultos religiosos, oferendas e velas foram vistas em alguns pontos do local (Figura 03).
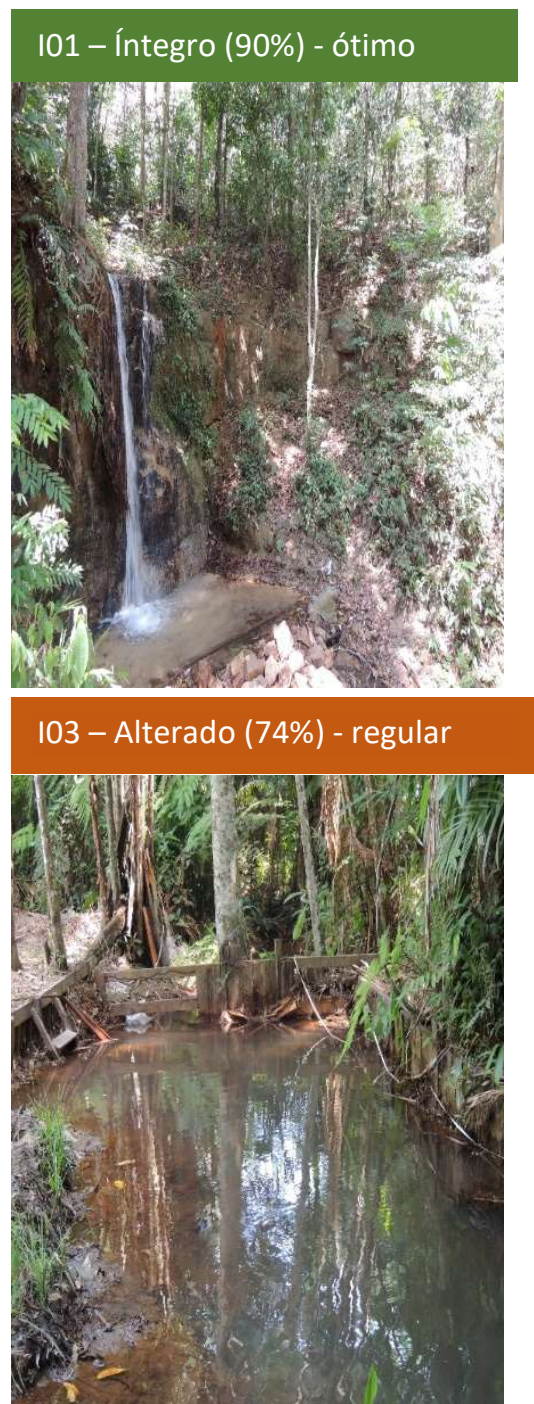

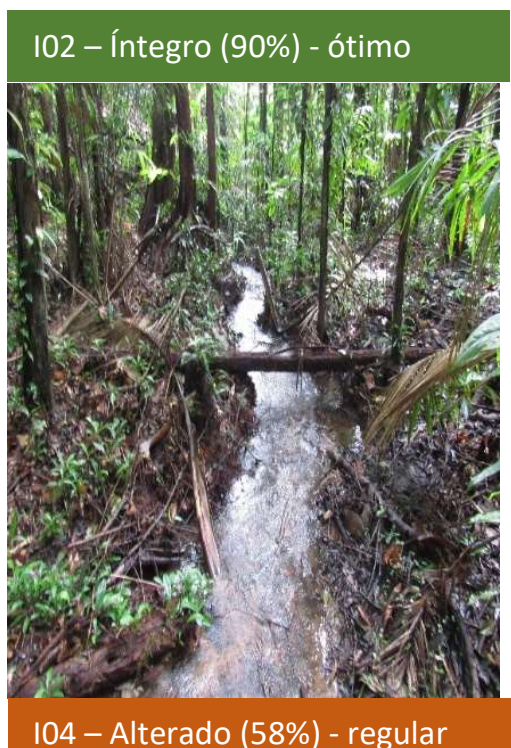

105 - Degradado (40\%) - ruim

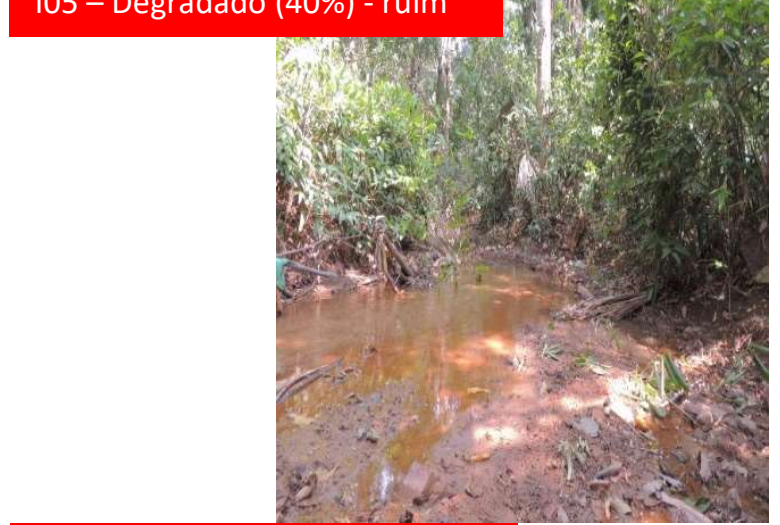

105 - Degradado (40\%) - ruim

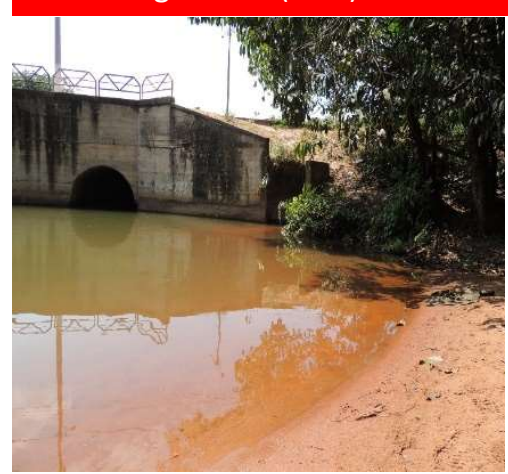

Figura 3: Pontos de coleta I01, 102, 103, 104 e 105 com seus respectivos Índice de Integridade Ambiental- IIH proposto por Nessimian (2008) ambiente íntegro é aquele que apresenta índice de integridade entre $85 \%$ e $100 \%$. Fonte: Projeto Igarapés Urbanos/CNPq/Edital Universal (2014).

De acordo com o IIH calculado, apenas duas nascentes foram consideradas íntegras, localizadas na microbacia do Irurá. A nascente que apresenta a maior integridade (102) é uma área particular, onde o proprietário mantém a mata ciliar e diz saber sobre a importância da mesma, segundo informações verificadas em campo. A outra nascente considerada íntegra (101) possui livre acesso e serve de local de 
recreação por apresentar uma pequena cachoeira. Foi notado em 101 a queima da mata ciliar, provavelmente porque ali ocorrem cultos religiosos (oferendas e velas foram encontradas em alguns pontos do local). Estes resultados indicam que devesse tomar medidas cabíveis para que se mantenha a integridade ambiental destes ambientes e a recuperação dos pontos $(103,104)$ alterados e $(105)$ degradados na microbacia do Irurá.

\section{Variação sazonal dos parâmetros físico - químicos}

$\mathrm{O}$ pH (Figura 4 A) teve maior variação e maiores valores no período seco e menores valores no período chuvoso. A variação espacial pH ao longo da bacia do Irurá, identificamos que as nascentes (I01 e 102) apresentaram pH ácido nos dois períodos analisados, sendo os menores valores encontrados no período seco. De acordo com a Resolução CONAMA n. 357/2005 estabelece que para águas doces o pH deve estar entre 6 e 9. De acordo com os dados encontrados nas nascentes (I01 e 102) todos os pontos apresentaram $\mathrm{pH}$ ácido, o que caracteriza as águas das nascentes como ácidas. Enquanto que nos pontos que se encontram mais distantes das nascentes (103, 104 e 105) foram encontrados os maiores valores de pH, estes pontos apresentam maior grau de urbanização e aporte de esgoto canalizado direto para o córrego, também nos pontos 104 e 105 foi possível visualizar a presença abundante de macrófitas aquáticas e algas, estes pontos não apresentaram variações entre os períodos seco e chuvoso.

A variação espacial do oxigênio dissolvido (Figura 4B) na microbacia do Irurá dividiu-se em dois grupos, as nascentes (101 e 102) apresentaram maiores valores e os demais pontos (103, 104 e 105) que se caracterizaram com os menores valores de oxigênio dissolvido. No período seco foi registrado o menor valor no 105 (3,7 mg/L/47,15\%), ponto com assoreamento e descarga de esgoto, com presença de galerias. No período chuvoso o maior valor encontrado foi no $101(9,7 \mathrm{mgL} / 120,6 \%)$, este ponto é uma nascente integra.

Na época seca pontos 103, 104 e 105 estão em desacordo com a Resolução do Conama n. 357/2005, para águas doces o OD devem estar não inferiores a $5 \mathrm{mg} / \mathrm{L}$, para a proteção da comunidade aquática. $\mathrm{Na}$ época de chuvas todos os pontos estão em acordo, devido ao aumento do fluxo de entrada no corpo d'água. A resolução Conama 357 informa que as águas limpas apresentam concentrações de OD elevadas, geralmente superiores a 5mg/L. O ponto 101 apresentou maior valor de OD, isto deve estar associado a característica desta nascente, área que se encontra com presença de rochas e queda d'água (cachoeira rocha negra) o que caracteriza a água bastante oxigenada. Já o ponto 102 é uma nascente que apresenta queda de água (cachoeira), porém com uma vazão menor comparada ao ponto I01.

Os menores valores de condutividade elétrica da água (Figura $4 C$ ) foram encontrados nas nascentes, ponto $101(15,5 \mu \mathrm{S} / \mathrm{s})$ e $102(12,9 \mu \mathrm{S} / \mathrm{s})$. Os dois locais apresentaram ambientes mais íntegros, com presença de mata ciliar e sem casas próximas. Enquanto, o menor valor de condutividade elétrica foi encontrado no ponto $105(53,5 \mu \mathrm{S} / \mathrm{s})$ durante o período seco.

O parâmetro turbidez (Figura 4D) apresentou variabilidade sazonal, variando no período chuvoso entre 0,13 e 7,81 NTU. No período seco, os valores variaram de 2,32 a 63,22 NTU. A variação espacial da turbidez na microbacia do Irurá dividiu-se em dois grupos, as nascentes (101 e 102) apresentaram menores valores e os demais pontos (104 e 105) que se caracterizaram com os maiores valores de turbidez. 
A vazão (Figura 4 E) apresentou variabilidade sazonal, com maior variação no período chuvoso, entre 0,00103 e $1,4 \mathrm{~m}^{3} / \mathrm{s}$. No período seco, os valores variaram de 0,00009 a $0,839 \mathrm{~m}^{3} / \mathrm{s}$. O Ponto $103\left(1,4 \mathrm{~m}^{3} / \mathrm{s}\right)$ apresentou o maior valore de vazão no período chuvoso. Este ponto fica próximo à BR - 163 e possui uma galeria de escoamento de água da chuva.

A temperatura (Figura 4 F) não apresentou variação sazonal, porém houve grande variação entre os pontos, com maior variação no período seco $101\left(26,15\right.$ e $\left.27,68^{\circ} \mathrm{C}\right)$. Os valores menores valores de temperatura da água estão foram encontrados nas nascentes, diretamente relacionados ao estado integro da vegetação e estrutura das nascentes, enquanto que nas áreas mais degradadas temos encontramos uma diferença de $1,5^{\circ} \mathrm{C}$.

(A)

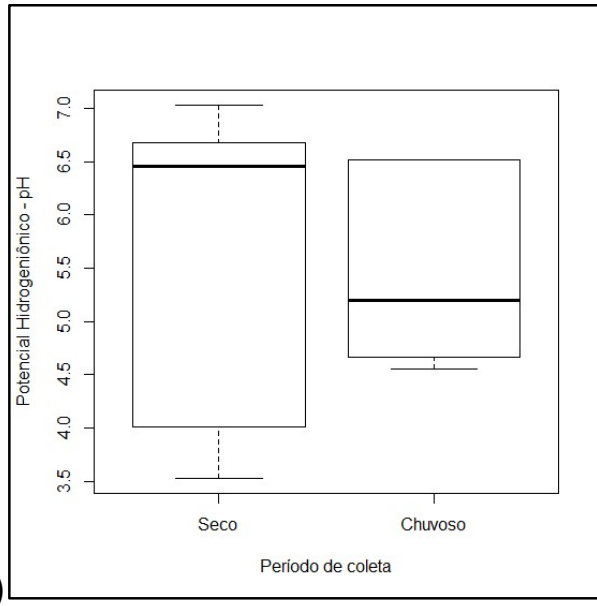

(C)
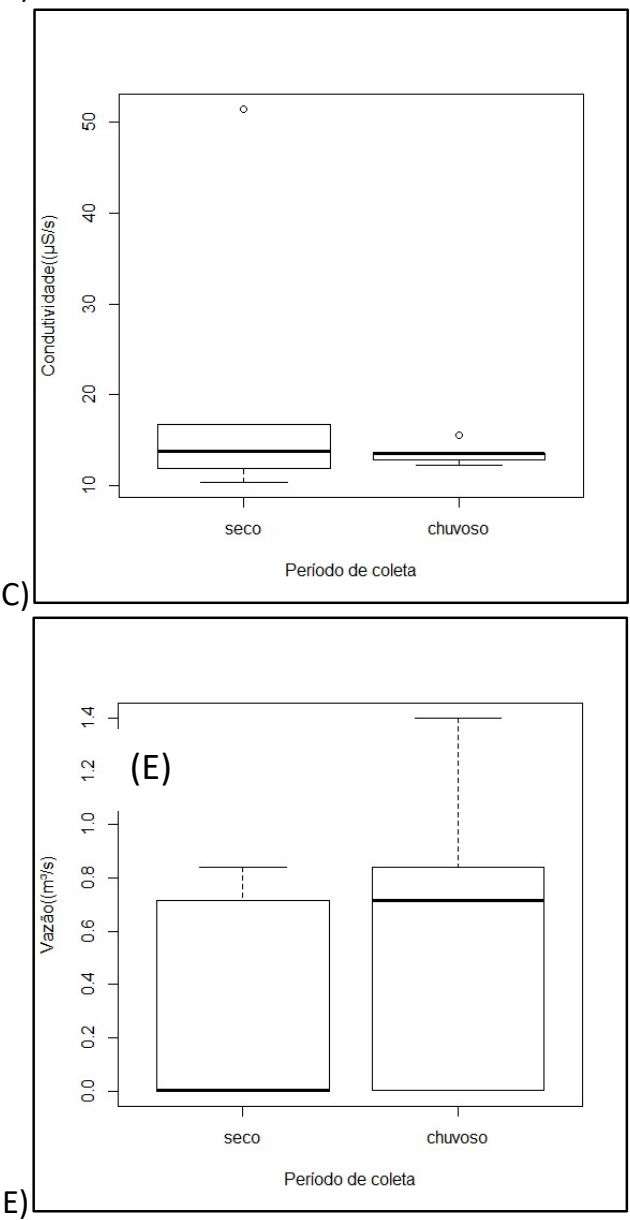

(B)

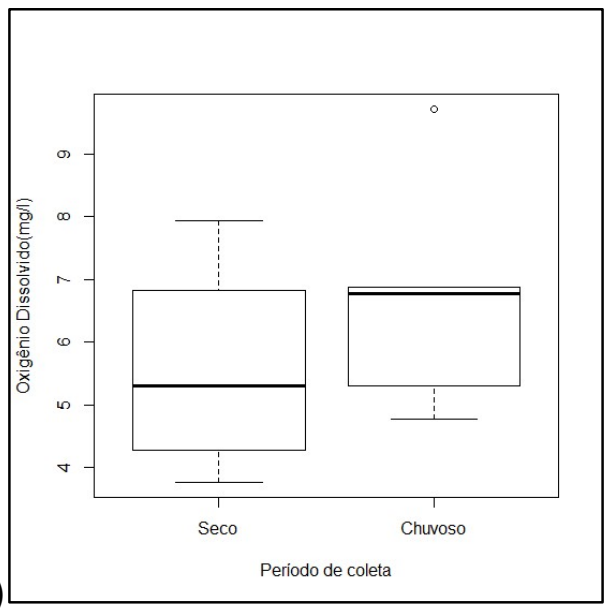

(D)
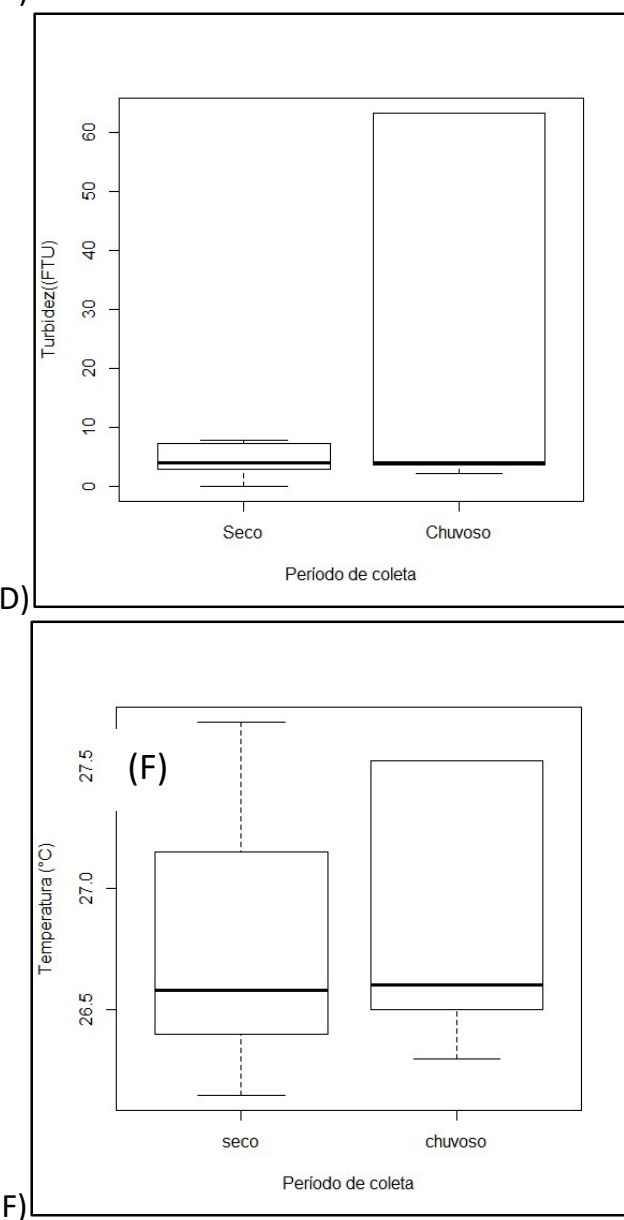
(G)

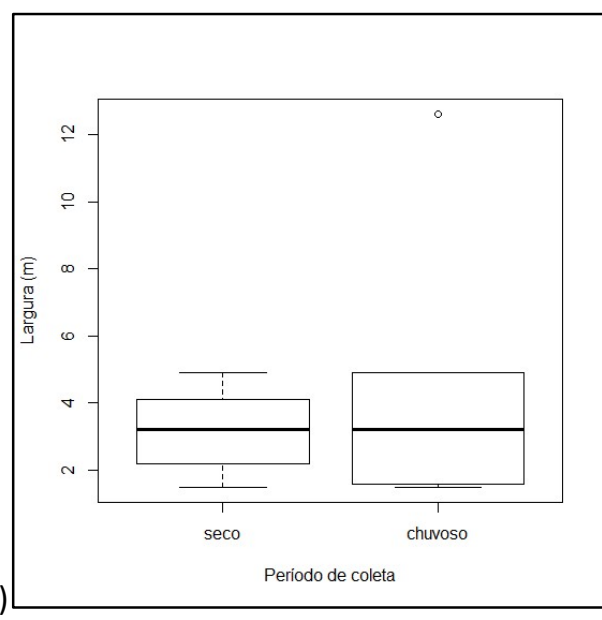

$(\mathrm{H})$

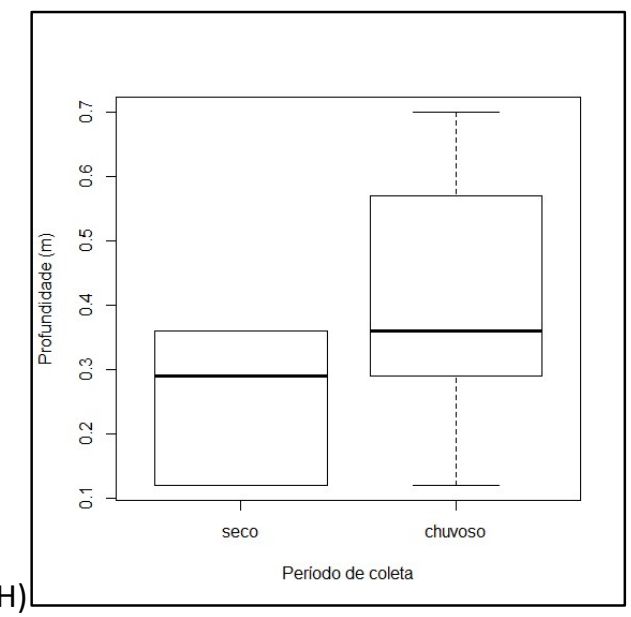

Figura 4: Avaliação comparativa entre os períodos sazonais. (A) potencial hidrogeniônico; (B) Oxigênio Dissolvido; (C) Condutividade; (D) Turbidez, (E) Vazão; (F) Temperatura; (G) Largura; (H) Profundidade.

O parâmetro profundidade (Figura 4G) apresentou variabilidade sazonal, variando no período chuvoso entre 0,12 a 0,70 m. No período seco, os valores variaram de 0,12 a 0,36 m. Com relação a variação espacial da profundidade na microbacia, destaca-se o ponto $104 \mathrm{com}$ menor profundidade no períod seco, este trecho é bastante assoreado. A maior profundidade foi registrada no ponto 105 durante o período chuvoso, ponto extremo da bacia, próximo a foz.

A largura (Figura 4H) apresentou variabilidade sazonal, sendo a maior largura registrada no período chuvoso com 105 (12,6 m), este ponto fica mais próximo a saída da bacia, enquanto que a menor largura foi registrada no ponto 102, localizado na nascente. Os pontos que apresentaram maior largura durante o período chuvoso estão relacionados a ambientes perturbados, com grau de assoreamento do canal, e consequentemente, alargamento do mesmo.

\section{Coliformes termotolerantes}

Na microbacia Irurá, nos pontos 103 e 104 ambos atingiram 92×102 NMP/100mL para CT, para CTT o valor foi de $2 \times 102 \mathrm{NMP} / 100 \mathrm{~mL}$ para o ponto I04. No ponto 104 da bacia do Irurá foi evidenciado durante as campanhas para coleta, focos de contaminação fecal da água. Os coliformes são usados como indicadores de qualidade da água por duas razões principais: são principalmente contaminantes água potável; a determinação do coliformes na água potável é relativamente simples e econômico (SARSAN, 2013). A Escherichia coli e o gênero Enterococos são melhores indicadores de contaminação fecal, em água doce e marinha, respectivamente (ANA, 2013). Os demais resultados pode ser visualizado na tabela abaixo (Tabela 4).

Tabela 4: Valores de NMP/100mL para coliformes e classificação da concentração de CTT da amostra de água analisada dos igarapés urbanos de Santarém no período chuvoso.

\begin{tabular}{|l|l|l|l|}
\hline \multirow{2}{*}{ Código } & NMP/100ml & Classificação $\left({ }^{*}\right)$ \\
\cline { 2 - 3 } & CT & CTT & \\
\hline 103 & $92 \times 10^{2}$ & $2 \times 10^{2}$ & \multirow{2}{*}{ Classe 1} \\
\hline 104 & $92 \times 10^{2}$ & 0 & \\
\hline 105 & $6,8 \times 10$ & $6,8 \times 10$ & \\
\hline
\end{tabular}

(*) Resolução CONAMA № 357/2005 e 274/2000; CTT - Coliformes totais/ambientais; CT - Coliformes Termotolerantes; EC - Escherichia coli. 
No ponto 103 devido ao resultado de qualidade microbiológica da água, com a presença de Escherichia coli as águas deste ponto se enquadram como classe 1, segundo as resoluções do CONAMA № 357/2005 e 274/2000. Neste ponto há presença de banheiro próximo ao local, residências e animais.

\section{Índice de degradação Ambiental}

Os resultados indicam correlações negativas entre o índice de integridade do habitat e a temperatura da água $(r=-0,90 ; p=0,083)$ (Figura $5 A)$, turbidez $(r=-0,90 ; p=0,083)$ (Figura $5 B$ ) a largura $(r=-0,90, p=$ 0,005 ) (Figura $5 \mathrm{C}$ ), estas não foram significativas. Porém, a integridade ambiental e a vazão apresentaram correlações positiva $(r=0,90 ; p=0,005)$ e significativas (Figura 5D).
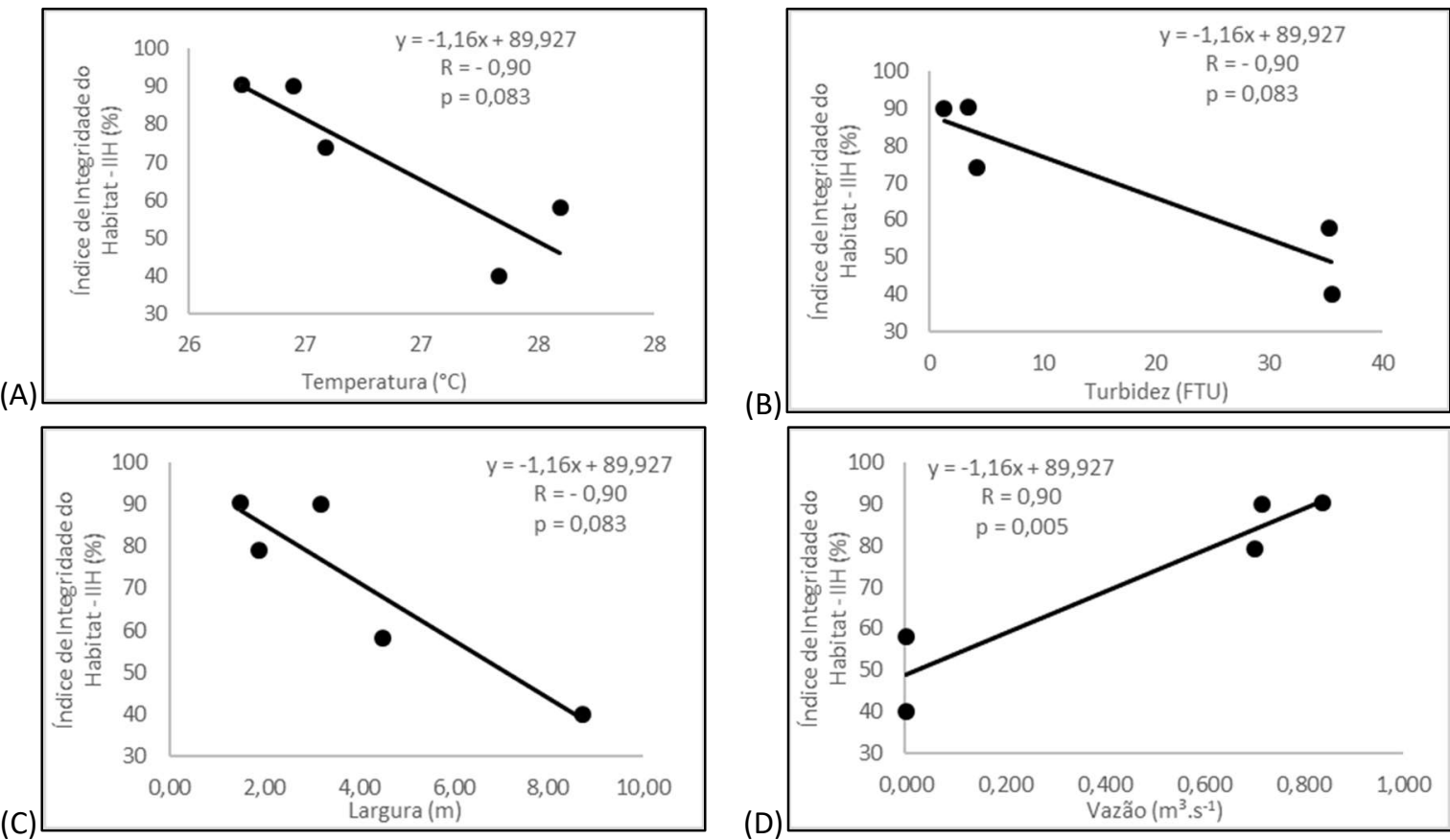

Figura 4: Correlação entre o índice de integridade do habitat e a temperatura (A), turbidez (B), largura do canal (C) e vazão (D).

A temperatura e a turbidez da água tendem a aumentar com o grau de degradação do habitat, nos pontos analisados. A largura do canal tende a aumentar com o grau de degradação ambiental, já a vazão foi correlacionada positivamente com a integridade ambiental, quanto maior a integridade maior a vazão, este fato é visualmente percebido, pois em ambientes não íntegros a largura do canal aumenta e consequentemente diminui a vazão. Neste estudo, a vazão $(r=0,90 ; p=0,005)$ teve correlação positiva significativa com IIH, os maiores valores de vazão foram encontrados a montante da bacia, onde localizamos lugares mais preservados. A jusante da bacia esperávamos que fossem registrados os maiores valores de vazão, porém, devido a degradação da estrutura física do igarapé, como aumento da largura e diminuição da profundidade, foram registrados os menores valores de vazão. Resultados similares foram encontrados por Mallin et al. (2009).

\section{DISCUSSÃO}

De maneira geral, os resultados fisiográficos (área, índices de drenagem, declividade e altitude) da 
bacia do Irurá são importantes para determinar a vulnerabilidade hidrológica da microbacia, como a propensão a sofrer enchentes. Com relação à integridade ambiental, apenas em duas nascentes apresentaram ambiente integro. A nascente (I02) é uma área particular e proprietário mantém a mata ciliar e sabe sobre a importância da mesma, informações estas verificadas em campo. A segunda nascente (I01) se encontra em área livre, porém, serve de recreação por apresentar uma pequena cachoeira, também, foi notado no local a queima da mata ciliar, pois este local também serve para cultos religiosos, oferendas e velas foram vistas em alguns pontos do local. Estes resultados indicam que se devem tomar medidas cabíveis para que se mantenha a integridade ambiental destes ambientes e a recuperação dos pontos $(103,104,105)$ degradados na microbacia do Irurá.

De acordo com a Resolução CONAMA n. 357/2005 estabelece que para águas doces o pH deve estar entre 6 e 9. De acordo com os dados encontrados nas nascentes (I01 e 102) todos os pontos apresentaram pH ácido, o que caracteriza as águas das nascentes como ácidas. Porém, na Amazônia é comum encontrarmos águas doces ácidas, devido a formação geológica (SIOLI, 1984). Enquanto que nos pontos que se encontram mais distantes das nascentes (103, 104 e 105) foram encontrados os maiores valores de pH, estes pontos apresentam maior grau de urbanização e aporte de esgoto canalizado direto para o córrego, também nos pontos 104 e 105 foi possível visualizar a presença abundante de macrófitas aquáticas e algas, estes pontos não apresentaram variações entre os períodos seco e chuvoso. $\mathrm{O}$ pH ácido tende a afetar as taxas de crescimento dos micro-organismos, enquanto que valores elevados podem estar associados à proliferação de algas em corpos d'água (VASCONCELOS et al., 2011).

Conforme os resultados apresentados as águas para o período analisado coloca-a na classe 1 , ou seja podem ser destinadas: a) à recreação de contato primário; b) à proteção das comunidades aquáticas; c) à aquicultura e à atividade de pesca; d) ao abastecimento para consumo humano após tratamento convencional ou avançado; e e) à irrigação de hortaliças que são consumidas cruas e de frutas que se desenvolvam rentes ao solo e que sejam ingeridas cruas sem remoção de película, e à irrigação de parques, jardins, campos de esporte e lazer, com os quais o público possa vir a ter contato direto. Enfatizando que no ponto 3 foi nas análises microbiológicas da água foram encontrados a presença de Escherichia coli que são melhores indicadores de contaminação fecal, por excreta humana. Os coliformes totais estão entre os indicadores mais frequentemente utilizados na análise microbiológica da qualidade da água inclusive para avaliação de potabilidade (BURGOS et al., 2014). A presença de coliformes tem sido associado a deteç̧ão de outros micro-organismos patógenos já relatada em outras pesquisas em águas (WU et al., 2011). É necessário monitoramento e tratamento nos períodos sazonais onde há maior risco de perdas na qualidade e prejuízos a saúde da população, onde os serviços como saneamento básico, coleta adequada e regular de resíduos sólidos deve ser acompanhada e especialmente nas fontes de abastecimento de água potável (COELHO et al., 2017).

De maneira geral, as nascentes com integridade ambiental mais preservada, localizadas na bacia do Irurá apresentaram valores de pH menores. Em estudo realizado por Ferreira et al. (2012) em igarapés preservados e urbanos, em Manaus/AM foi encontrado valores de pH variando de 4,1 a 4,9 (ácido) em 
ambientes com floresta primária intacta ou com pouca ação antrópica e valores mais elevados variando de 6,1 a 7,3 em ambientes influenciados pela urbanização.

Na época seca pontos 103, 104 e 105 estão em desacordo com a Resolução do Conama n. 357/2005, para águas doces o OD devem estar não inferiores a $5 \mathrm{mg} / \mathrm{L}$, para a proteção da comunidade aquática. $\mathrm{Na}$ época de chuvas todos os pontos estão em acordo, devido ao aumento do fluxo de entrada no corpo d'água. A resolução Conama 357 informa que as águas limpas apresentam concentrações de OD elevadas, geralmente superiores a $5 \mathrm{mg} / \mathrm{L}$. O ponto 101 apresentou maior valor de OD, isto deve estar associado a característica desta nascente, área que se encontra com presença de rochas e queda d'água (cachoeira rocha negra) o que caracteriza a água bastante oxigenada. Já o ponto 102 é uma nascente que apresenta queda de água (cachoeira), porém com uma vazão menor comparada ao ponto I01. Assim, é possível verificar que os pontos com maiores valores de OD são as nascentes, que mantém a integridade ambiental mais preservada e que os valores de OD decrescem nos trechos mais impactados e com presença de urbanização ao redor. Estes resultados corroboram aos encontrados por Melo et al. (2005) para igarapés na cidade de Manaus AM. Segundo Vasconcelos et al. (2011) o oxigênio dissolvido acaba sendo o maior indicador da poluição gerada pela atividade antrópica, constataram em suas coletas que valores inferiores eram normalmente encontrados em coletas mais próximas a áreas antropizadas, e onde havia lançamento direto de matéria orgânica e outras substâncias.

Segundo a Agencia Nacional de Águas, as condutividades de águas doces naturais devem estar abaixo de $500 \mu \mathrm{SCM}^{-1}$ e dentro dos padrões exigidos pela CONAMA $n$ ㅇ 357/2005, valores superiores podem indicar entrada de poluentes domésticos e industriais na água. Neste estudo somente o ponto 105 apresentou valor acima do permitido, neste ponto o córrego apresenta grau de assoreamento, solo exposto à contaminação, durante as chuvas, sólidos inorgânicos são carreados para dentro do ambiente. Nos demais ponto a condutividade é maior na época seca. No geral, as maiorias dos pontos estão dentro do permitido pelo CONAMA no 357/2005. Segundo Costa (2012) o uso excessivo do solo, aumenta a condutividade elétrica. A condutividade elétrica mede a capacidade que a água tem de transmitir corrente elétrica e está diretamente relacionada à concentração de espécies iônicas dissolvidas, principalmente inorgânicas (ANA, 2013).

Altos valores de turbidez podem influênciar na fotossintese, e crescimento do plâncton de plantas aquáticas (LIMA, 2005). Somente na época de chuvas os pontos 104 e 105 tiveram valores de turbidez altos. $\mathrm{Na}$ época de chuvas os sedimentos são carreados fazendo os valores de turbidez elevarem (ANA, 2013). Todos os pontos estão dentro do permitido pela Resolução Conama 375/2005 limite máximo de 100 UNT. Altos índices pluviométricos ocasionam a diluição das cargas poluidoras em corpos d'água (GIATTI, 2004).

Este ponto fica próximo à BR - 163 e possui uma galeria de escoamento de água da chuva. Esta variável é importante para o monitoramento da qualidade e quantitade de água das nascentes, que funciona como um indicador da degradação ambiental das nascentes. Segundo, Pereira (2016) em estudo realizado em igarapés urbanos em Manaus apontou que a influência antrópica nos igarapés que cortam a área urbana de Manaus reflete no aumento da vazão. A vazão é uma medida hidrológica fundamental, permite uma primeira aproximação dos problemas, muito importante para o monitoramento da qualidade e quantidade 
de água dos corpos hídricos, que funciona como um indicador da degradação ambiental (TUCCI, 2009). A vazão do manancial influencia na qualidade da água, tende a piorar com a diminuição da vazão e do efeito de diluição, ocorrendo a concentração dos poluentes (TORRES et al., 2009).

Carvalho (2011) encontrou em estudos em igarapés de Santarém/PA encontrou que a integridade dos igarapés apresentou uma relação com as variáveis de habitat físico. As variáveis de habitat físico também apresentaram um gradiente de distribuição, sendo a categoria degradada a que mais se diferenciou. Neste estudo os valores mais altos de temperatura da água estão relacionados a pontos da bacia que se encontra em estado degradado, este problema reflete no aumento da temperatura da água que se agrava no período menos chuvoso.

Os pontos que apresentaram maior largura durante o período chuvoso estão relacionados a ambientes perturbados, com grau de assoreamento do canal, e consequentemente, alargamento do mesmo. Em estudo realizado em igarapés em Santarém/PA as correlações mais fortes entre as métricas do Índice de Integridade Biótica e as variáveis ambientais foram com as variáveis que descreviam as dimensões físicas ou características geomorfológicas do canal (dados do talvegue, profundidade, largura molhada, sinuosidade, declividade e complexidade do hábitat) estas variáveis desempenham um papel importante na determinação da estrutura de comunidades de peixes (CARVALHO, 2011). A largura e profundidade do canal são variáveis que implicam nos valores de vazão (TUCCI, 2009).

\section{CONCLUSÕES}

Foi possível, captar o índice de degradação ambiental ao longo da microbacia do Irurá causada pela urbanização e a falta de saneamento ambiental. O índice de integridade do habitat apresentou-se como uma boa ferramenta para estimar a qualidade ambiental ao longo da microbacia, indicando a perda de vazão a jusante da bacia causada pela degradação ambiental. Ações para prevenir a degradação nos ambientes considerados íntegros e para minimizar e reverter as fontes de impacto que promovem a degradação da microbacia do Irurá são necessárias.

\section{REFERÊNCIAS}

APHA. American Public Health Association. Standard methods for the examination of water and wastewater. 22 ed. Washington: APHA, 2002.

ANJOS, H. D. B.. Efeitos da fragmentação florestal sobre assembleias de peixes de igarapés na zona urbana de Manaus, Amazonas. Mestrado (Dissertação) - Universidade Federal do Amazonas, Manaus, 2007.

ANA. Agência Nacional de Águas. Parâmetros de qualidade de água. ANA, 2013.

BURGOS, T. N.; SCHUROFF, P. A.; LOPES, A. M.; LIMA, N. R.; PELAYO, J. S.. Água de consumo humano proveniente de poços rasos como fator de risco de doenças de veiculação hídrica. Revista de Ciências da Saúde, São Luís, v.16, n.1, p.34-38, 2014.
BLEICH, M. E.; MORTATI, A. F.; ANDRÉ, T.; PIEDADE, M. T. F. Riparian deforestation affects the structural dynamics of headwater streams in Southern Brazilian Amazonia. Tropical Conservation Science, v.7, n.4, p.657-676, 2014.

BRASIL. Ministério do Meio Ambiente. Caderno da Região Hidrográfica Amazônica. Brasília: Secretaria de Recursos Hídricos, 2006.

BRASIL. Lei n. 12.651, de 25 de maio de 2012. Revoga a Lei n. 4.771 , de 15 de setembro de 1965, que dispõe sobre a proteção da vegetação nativa. Brasília: DOU, 2012.

BRASIL. Resolução CONAMA n. 357, de 17 de março de 2005. Brasília: Ministério do Meio Ambiente, 2005.

COELHO, S. C.; DUARTE, A. N.; AMARA, L. S.; SANTOS, P. M.; SALLES, M. J.; SANTOS, J. A. A.; MARTINS, A. S.. 
Monitoramento da água de poços como estratégia de avaliação sanitária em Comunidade Rural na Cidade de São Luís, MA, Brasil. Ambient \& Ague an Interdisciplinary Journal of Applied Science, Taubaté, v.12, n.1, p.156-167, 2017.

CARVALHO, D. R.. Relação entre habitat físico, uso e ocupação do solo e riqueza de espécies de peixes em igarapés da região de Santarém, Pará. Monografia (Bacharelado) - Universidade Federal de Lavras, Belo Horizonte, 2011.

CARVALHO, M. S.; MANNICH, M.; PINTO, B. V.; CUNHA, C. M. I.. Variação nictemeral de qualidade da água em rios urbanos: implicações no monitoramento. REGA, Porto Alegre, v.13, n.2, p.129-141, 2016.

CORRÊA, J. M.; GERHARD, P.; FIGUEIREDO, R. O.. Ictiofauna de igarapés de pequenas bacias de drenagem em área agrícola do Nordeste Paraense, Amazônia Oriental. AmbiÁgua, Taubaté, v.7, n.2, p.214-230, 2012. DOI: http://dx.doi.org/10.4136/ambi-agua.739

COSTA, F. G. C.. Análise Preliminar de Parâmetros FísicoQuímicos em Águas Fluviais em Duas Mesobacias Hidrográficas no Nordeste Paraense. Boletim da EMBRAPA, 2012.

ESTEVES, F. A.. Fundamentos de limnologia. 3 ed. Rio de Janeiro: Interciência, 2011.

FEARNSIDE, P. M.. Deforestation in Brazilian Amazonia: history, rates and consequences. Conservation Biology, v.19, n.3, p.680-688, 2005

FERREIRA, S. J. F.; MIRANDA, S. A. F.; MARQUES FILHO, A. O.; SILVA, C. C.. Efeito da pressão antrópica sobre igarapés na Reserva Florestal Adolpho Ducke, área de floresta na Amazônia Central. Revista Acta Amazônica, v.42, n.2, p.533540, 2012.

GALUCH, A. V.. Adaptação de um índice de integridade biótica para igarapés da Amazônia Central, com base em atributos ecológicos da comunidade de peixes. Dissertação (Mestrado) - Universidade Federal do Amazonas, Manaus, 2007.

GIATTI, L. L.. Condições de saneamento básico em Iporanga, estado de São Paulo. Revista de Saúde Pública, São Paulo, v.38, n.4, p.571-577, 2004.

GUARIDO, P. C. P.. Degradação ambiental e presença de espécies de peixes não nativas em pequenos igarapés de terra firme de Manaus, Amazonas. Dissertação (Mestrado em Biologia de Água Doce e Pesca Interior) - Instituto Nacional de Pesquisas da Amazônia, Manaus, 2014.

LIMA, M. A. S.. Águas acumuladas em açudes e barragens na região de Santa Maria e flutuações em seus atributos físico químicos. Dissertação (Mestrado em Ciências Rurais) Universidade Federal de Santa Maria, Santa Maria, 2005.

MALLIN, M. A.; JOHSON, V. L.; ENSIGN, S. H.. Comparative impacts of stormwater runoff on water quality of an urban, a suburban, and a rural stream. Environ Monit Assess, v.159, p.475-491, 2009.
MARMONTEL, C. V. F.; RODRIGUES, V. A.. Parâmetros Indicativos para Qualidade da Água em Nascentes com Diferentes Coberturas de Terra e Conservação da Vegetação Ciliar. Floresta e Ambiente, P.171-181, 2012.

MELO, E. G. F.; SILVA, M. S. R.; MIRANDA, S. A. F.. Influência antrópica sobre águas de igarapés na cidade de Manaus Amazonas. Revista Caminhos de Geografia, n.5, v.16, p.4047, 2005.

MENDONÇA, F. P.. Ictiofauna de igarapés de terra firme: estrutura das comunidades de duas bacias hidrográficas, Reserva Florestal Ducke, Amazônia Central. Dissertação (Mestrado) - Instituto Nacional de Pesquisas da Amazônia, Manaus, 2001.

MENDONÇA, F. P.; MAGNUSSON, W. E.; ZUANON, J.. Relationships between Habitat Characteristics and Fish Assemblages in Small Streams of Central Amazonia. Copeia, n.4, p.750-763, 2005.

MONTEIRO, M. C.; PEREIRA, L. C. C.; GUIMARÃES, D. O.; COSTA, R. M.; SOUZA-FILHO, P. W. M.; VIEIRA, S. R.. Influence of natural and anthropogenic conditions on the water quality of the Caeté river estuary (North Brazil). Journal of Coastal Research, v.64, p.1535-1539, 2011.

NESSIMIAN, J. L.; VENTICINQUE, E. M.; ZUANON, J.; MARCO JUNIOR, P.; GORDO, M.; FIDELIS, L.; BATISTA, J. D.; JUEN, L.. Land use, habitat integrity, and aquatic insect assemblages in Central Amazonian streams. Hydrobiology, v.614, p.117131, 2008.

OLIVEIRA JUNIOR, J. M. B.. O Efeito de da alteração ambiental sobre assembleias de Odonata na Amazônia Oriental. Dissertação (Mestrado em Ecologia e Conservação) - Universidade Federal do Estado de Mato Grosso, Nova Xavantina, 2013

PARÁ. Sistema de Gerenciamento de Recursos Hídricos do Estado do Pará/Brasil/Secretaria de Estado de Meio Ambiente. Belém: SEMA, 2012.

PEREIRA, B. W. F.; MACIEL, M. N. M.; OLIVEIRA, F. A.; ALVES M. A. M. S.; RIBEIRO, A. M.; FERREIRA, B. M.; RIBEIRO, E. G.

$P$.. Uso da terra e degradação na qualidade da água na bacia hidrográfica do rio Peixe-Boi, PA, Brasil. Ambi-Agua, v.11, n.2, p.14, 2016. DOI: http://doi.org/10.4136/ambiagua.1802

R CORE TEAM. R: A language and environment for statistical computing. Vienna: R Foundation for Statistical Computing, 2014.

SARSAN, S.. Effect of storage of water in different metal vessels on coliforms. International Journal of Current Microbiology and Applied Sciences, v.2, n.11, p.24-29, 2013.

SIOLI, H.. The Amazon and its main affluents: Hydrography, morphology of the river courses and river types. In: SIOLI, H.. The Amazon limnology and landscape ecology of a might tropical river and its basin. Dordrecht: Dr. W Junk Publishers, 1984. p.127-165.

SNIS. Sistema Nacional De Informações Sobre Saneamento. Ranking do saneamento das $\mathbf{1 0 0}$ maiores cidades do Brasil. Brasília: SNIS, 2015. 
TARGA, M. S.; BATISTA, G. T.; DINIZ, H. D.; DIAS, N. W.; MATOS, F. C.. Urbanização e escoamento superficial na bacia hidrográfica do Igarapé Tucunduba, Belém, PA, Brasil. AmbiÁgua, Taubaté, v.7, n.2, p.120-142, 2012.

TORRES, J. L. R.; SILVA, S. R.; PEDRO, C. A. S.; PASSOS, A. O.; GOMES, J. Q.. Morfometria e qualidade da água da microbacia do ribeirão da Vida em Uberaba/MG. Global Science and Technology, v.2, n.1, p.1-9, 2009.
TUCCI, C. E. M.. Hidrologia: Ciência e Aplicação. 4 ed. ABRH, 2009.

VASCONCELOS, V. M. M.; SOUZA, C. F.. Caracterização dos parâmetros de qualidade da água do manancial Utinga, Belém, PA, Brasil. Ambi-Água, Taubaté, v.6, n.2, p.305-324, 2011. DOI: http://doi.org/10.4136/ambiagua.202

WU, J.; LONG, S. C.; DAS, D.; DORNER, S. M.. Are microbial indicators and pathogens correlated? A statistical analysis of 40 years of research. Journal of Water and Health, v.9, n.2, p.25-78, 2011.

A CBPC - Companhia Brasileira de Produção Científica (CNPJ: 11.221.422/0001-03) detém os direitos materiais desta publicação. Os direitos referem-se à publicação do trabalho em qualquer parte do mundo, incluindo os direitos às renovações, expansões e disseminações da contribuição, bem como outros direitos subsidiários. Todos os trabalhos publicados eletronicamente poderão posteriormente ser publicados em coletâneas impressas sob coordenação da Sustenere Publishing, da Companhia Brasileira de Produção Científica e seus parceiros autorizados. Os (as) autores (as) preservam os direitos autorais, mas não têm permissão para a publicação da contribuição em outro meio, impresso ou digital, em português ou em tradução. 